shall have to speak hereafter, you will try a smaller instru. ment of the same kind until you have arrived at one which does pass through and inwards into the bladder. But you may also test your observation by passing a soft tapering French bougie-11 or 12 English size,-and if it is a natural obstacle which at first checked your blunt-pointed bougie, the former instrument will probably slip through without trouble.

Now, with reference to these bulbous-pointed flexible explorers, nothing is more easy, especially with an unpractised hand, than to deceive oneself with respect to the existence of stricture by means of them. If not drawn out accurately in the axis of the passage, you may feel a check, and readily find what you believe to be a stricture in the most healthy urethra. And that is precisely what $I$ am so anxious to guard you against; for, in the hands of designing persons, these instruments may be turned to most un. worthy purpose. For wen outside the ranks of our profession, or bolding a questionable position on its outskirts, these instruments are the very thing. That is an additional reason why we should be careful not to encourage their unnecessary use. I have used small bulbous instruments in metal for the diagnosis of narrow and confirmed stricture, on which it is desirable to operate, for twenty years, but for slight stricture never; and I have protested against their use on the two grounds already named: first, that for such the instrument inflicts needless pain; secondly, that it is liable to deceive a young operator not too adroit or familiar with its use.

But now, in the second case-not that of the young man, but of the patient who has a confirmed stricture, - the diagnosis has probably to be conducted with more attention to detail. I proceed as follows, making what may be called a "survey" of the passage. I commence by passing the soft, blunt-ended English gum-elastic bougie as far as it will go; and when this stops, as it may do within an inch or less of the orifice, I make a note of the distance, and next find what will pass with tolerable ease through the obstruction met with. Very likely a No. 4 or 5 (similar instrument to the preceding) will do so, and it may then be carried further to seek another check, which is not unfrequently met with at about five inches from the orifice. Through this, after a trial or two, a very small gum cathe. ter-say No. 1 or 2-may probably be passed into the bladder, drawing off some urine, and so assuring you of its position. I know then the patient has, at all events, a narrowing near the orifice and another at the distance named. I may verify this at once with a bulbous instrument if $I$ choose; but as long as the anterior narrowing exists, it is as well to postpone more minute research until it is divided, as considerable narrowing at that part always requires to be. Such a one, indeed, is never advantageously treated by dilatation. This being done, the No. 11 bluntended bougie is passed, and we learn whether any contraction exists in the interval existing between it and the spot originally marked at five inches. If there is one, the stopping of the bougie will indicate its situation. But if the bougie passes easily to the point just named, the canal is sufficiently open, and we have arrived at what, in ninetynine cases out of a hundred, is the only remaining stricture; for it is rare indeed, where a narrow stricture exists at that distance from the meatus, that any other will be found beyond. This has next to be dealt with, and, as we are speaking now of old and confirmed cases, there is little doubt that the best treatment will be internal urethrotomy. How to accomplish that most perfectly will be discussed in my lecture on that subject.

A word or two about the bulbous exploring instrument. It should, in my opinion, be of polished metal mounted on a slender metal rod or shaft. No other material slides so easily and smoothly through the urethra; and the necessity for it is, after all, not great, so that to employ one which produces much irritation, passes roughly, or distends unnecessarily, is to pay too high a price for the small amount of information it may convey. I am free to say that, although I used the metal bulbous instruments in the earlier part of my career, I can now, with more experience, attain all that is necessary without them. It is said that they enable you to ascertain the length of a stricture. In reference to this, let we tell you, first, that considerable narrowing almost never affects the urethra for any great distance. The passage is often partially implicated for half an inch behind and half an inch before the maximum point of narrowing-an important practical point in relation to operation; but the very narrow spot, which is what the exploring bulb indicates, is almost invariably short, within a quarter of an inch in extent. Secondly, you must take into consideration the fact that the mobility of the mucous lining of the urethra will deceive you if you are not aware of it. A very little pressure in front, on entering the stricture, or from behind, in withdrawing the exploring bulb, if it comes rather tightly through, changes the situation of the contracted portion considerably in relation to its distance from the external meatus.

I repeat, then, if you have to deal with a recent stricture, such a one as you naturally intend to treat by dilatation, the introduction of a large bulbous explorer is wholly useless, only produces unnecessary pain, and tends to excite. inflammation.

But in view of any internal incisions for a confirmed or obstinate case, the important thing is simply to know where the narrowed points of the urethra are, and then it is not difficult to apply your cutting instrument properly to them.

But, before proceeding further, I wish to show you the proper mode of passing an instrument through the bealthy urethra into the bladder, so as to avoid error arising from certain sources of difficulty which are naturally found there, and are often mistaken for stricture. Were the urethra a mere tube of uniform diameter, these would not exist. We shall observe in the particulars of its unlikeness to a simple tube, that such natural obstacles do exist. and have to be avoided.

\section{ON CHLORIDE OF LEAD AS A DEODORISER AND DISINFECTANT.}

\section{BY R. H. GOOLDEN, M.D.}

I wISH to call the attention of medical practitioners and especially of sanitary officers, through THE LANCET, to the value of chloride of lead as the most powerful and economical agent for eliminating sulphide of hydrogen from the atmosphere, as well as from all organic matter in a state of decomposition or putridity. There is nothing new in this fact. It is known to all chemists, but its application has been practically disregarded, owing to the popularity of other deodorisers, which having been made the subjects of patents are well advertised, and therefore generally adopted, and they certainly do answer the purpose with more or less completeness. Of these I may instance-Chloride of zinc (Burnett's), chloride of aluminium, hypochlorite of soda (Marvel Fluid), hypochlorate of potassa, hypochlorate of lime, permanganate of potassa (Condy's), permanganate of lime, peroxide of iron, peroxide of manganese, powdered. charcoal, bog earth, and alluvial earth.

I need not enter into the rationale of the chemical action of these several ingredients, nor do I suggest the substitution of chloride of lead for the three last-named substances when it is proposed to convert organic matter into reproductive soil for farming or gardening purposes, but only in those cases where it is necessary to purify a fetid atmosphere, which has to be breathed by living people.

It has already been objected that zinc and manganese have been detected in plants grown in soil manured by stable-dung, which had been deodorised by Burnett's and Condy's fluids. I do not know how far the fact has been established, but even the suggestion is of such importance as to make us very careful in proposing the use of lead, unless it can be shown that lead is not in the same category. I think we may arrive at a strong inductive probability that it is not so ; for the lead sulphide is quite insoluble except in strong nitric acid, in boiling hydrochloric acid, and in aqua regia (which is not the case with zinc or manganese); nor is lead sulphide absorbed in the human body when swal lowed, but passes on by the bowel as harmless as powdered charcoal; and the affinity of lead for sulphur is so strong that lead sulphide cannot be resolved but at a very high tempe- 
rature. Another safeguard lies in the very sparing solubility of lead chloride, and also in the very small quantity ased in the deodorising process.

The chloride of lead and sulphide of hydrogen react with a simultaneous double affinity, producing an insoluble lead oulphide and hydrochloric acid. Lead is so readily acted upon by sulphur, that metallic lead and oxide of lead in paint, even when protected by the dried oil, is turned black in any atmosphere where sulphide of hydrogen exists. White paint in stables, waterclosets, and in artists' paintings, is soon turned black by it and spoilt.

To prepare it for use, take, for ordinary purposes, half a drachm of nitrate of lead, dissolve it in a pint or more of boiling water-(nitrate of lead is a soluble salt, and very cheap; it may be had in any quantity for about a shilling a pound, and should be much cheaper if bought in large quantities), -and dissolve two drachms of common salt (chloride of sodium) in a pail or bucket of water ; pour the two solutions together, and allow the sediment to subside. The clear supernatant fluid will be a saturated solution of chloride of lead. A cloth dipped in this solution and hung up in a room will sweeten a fetid atmosphere inatantaneously, or the solution thrown down a sink, watercloset, or drain, or over a heap of dung or other refuse, will produce a like result. Even the tarnishing of gold and silver plate may be prevented by a rag dipped in the solution being hung up in the room or window where it is exposed.

It will thus be seen that one great advantage of chloride of lead over all other deodorisers lies in its great cheapness. The cost of the quantity of nitrate of lead required for use may be estimated at a fraction of a farthing; it is easily carried about, or may be sent by post; it is a dry solid, is not caustic, nor will it discolour or blister the skin; it can be kept in paper or a pill-box, and therefore does not require a glass or other fragile bottle. The exact equivalent proportion of nitrate of lead and chloride of sodium would be 100 to 317 in weight. As it is necessary that the whole of the nitrate of lead should be converted into chloride, a slight excess of salt is desirable, but as chloride of sodium in the solution renders the chloride of lead even less soluble than in water, I have adopted the weights respectively as half a drachm to two drachms-sufficiently correct for all practical purposes. 331 grains of nitrate of lead converted into lead chloride are sufficient for 34 grains of sulphide of hydrogen. Now $36^{*} 38$ grains of sulphide of hydrogen represents 100 cubic inches-a quantity quite ten times larger than under ordinary circumstances we are likely to have to deal with.

In sick rooms, hospitals, and crowded assemblies, we have to deal with the sulphide of hydrogen and ammonium, given off by the resolution of organic, especially albuminous matter in decay, or eliminated from the living body in fæces through the skin and with the breath; and it must be borne in mind that whenever great numbers of people are crowded together in rooms, as in balls, concerts, theatres, or schoolrooms, the human body gives off an amount of sulphide of hydrogen, and that it is this, and not the carbonic acid, that makes people exposed to such an atmosphere so depressed, and which, when highly concentrated, developes typhus poison. The quantity is indeed very slight compared with its power of offensiveness, as in the analogous case of various flowers whose scent is most powerful, producing a sensible effect upon the human organism, and yet the agreeable or offensive matter composing it is too small to be detected by any test except the olfactory sense; and hence it is that the small quantity of lead chloride contained in the solution is found practically to be quite sufficient to sweeten the most offensive room, and, in my experience, to deodorise any drain, watercloset, or sink.

A not less important direction, in which the use of the chloride of lead would prove of the utmost value to H.M. navy and the mercantile marine, is for the purification of Bilge-water, and of the close, fetid atmosphere between decks in emigrant and passenger ships; easy of transport, occupying little room, and safely stowed away in paper or wooden boxes. The sea-water requiring no addition of salt, the solution is made without trouble, and need merely be thrown down into the bilge, where the ship's motion completes the process.

The following cases, which have occurred in my own prectice, will illustrate its use and successful application :-
CASE 1.-A lady living in Chester-square, who was suffering from sciatica, consulted me many years ago, and my attention was called to a large tumour in the external part of the hip-joint. The tumour was soft and not very prominent, had been very gradually increasing, and with its increase the sciatic pains became more severe. Believing it to be a fatty tumour pressing on the sciatic nerve, I could only refer her to a surgeon for its removál. It was accordingly removed by Mr. Lane, and without any hæmorrhage at the time, and proved to be a large fatty tumour the size of a child's head. The sciatic pains ceased, and the patient appeared to be in a fair way to recover speedily the effect of the operation. A bout a week afterwards I was asked to meet Mr. Lane, and found that the cavity from which the tumour had been removed had been distended with blood in a state of decomposition, the patient suffering all the symptoms of blood-poison: small rapid pulse, black sordes coating the mouth, tongue, lips, and nose; wandering, muttering delirium; she would take no food. The room was most offensive, the smell penetrating to the passages and other rooms. Basins containing Condy's fluid, Burnett's fluid, and bog-earth were in various parts of the room, but exercised but little influence over the fetid emanation.

Wishing to try the effect of the lead chloride, we obtained, with great difficulty, a small quantity of nitrate of lead, and prepared the solution as above described. A towel dipped in it was hung up in the room, and instantaneousty the smell disappeared. The wound was dressed, and over the wound some lint dipped in the solution was placed. The next day we met, and found our patient sitting up in bed, quite cheerful, with a clean tongue and good pulse, enjoying a mutton-chop and some port wine. The room was perfectly free from smell.

I have had many other opportunities of using this solution with equally satisfactory results, especially in paralytic cases, where, towards the end, the fetor of the breath and emanations from the skin are most offensive.

CASE 2,-Three years ago, after a very severe stormshower, the large drain at the back of the United University Club was burst by the flood, and opened to the atmosphere. A more distressing smell in its immediate neighbourhood could hardly be imagined. Carbolic acid was used in the Club, which substituted only one stink for another. I sent the steward for a pound of nitrate of lead, of which half an ounce was used. A towel wetted with the solution was hung up in each room, and the rest poured down the drains and into the sewer, and immediately all smell was gone. The neighbours, who were unaware of what was being done, expressed the greatest surprise at the sudden disappearance of the nuisance. Although the drain remained open for some days until it could be repaired, there was no more inconvenience felt from the smell.

Case 3.-The wife of a horse-jobber in a very large way of business, apparently suffering from the poison of carbolic acid used to disinfect the stables where she lived, consulted me. She informed me that although the stables were welldrained and well-ventilated, the effuvium from the large number of horses and the accumulation of dung was so offensive that they had been induced to use carbolic acid, which, though painfully disagreeable, was not so offensive as the stable exhalations had been. It appeared also that since the use of carbolic acid they had lost seventeen horses, and that they could not help connecting their loss in some way with it. I recommended the immediate disuse of the carbolic acid, and in its place to try the nitrate of lead and salt. In a fortnigbt I saw her again in perfect health, and learnt that the stables had, from the first application, become freed from all disagreeable odour, and that the dung-pits into which some of the solution was regularly sprinkled were now sweet, to the great contentment of the horsekeepers and stablemen, with whom the removal of the dung has always been a subject of great difficulty.

CASE 4.-Sume years ago, when visiting one of H.M. largest ships, I casually heard loud complaints of the nuisance caused by the bilge water. Through the courtesy of the officers, which was greater than their faith in any possible remedy, I was allowed to try the experiment of removing it, and, having procured half an ounce of nitrate of lead, it was dissolved in a bucket of boiling fresh water, and thrown down the bilge when the ship was rolling slightly. The effect was the instantaneous disappearance of all smell a large white precipitate, which immediately afterwards 
became black, subsided to the bottom, and the bilge-water became perfectly clear. The cost was one halfpenny.

I have selected these few cases as leading types of the application and results of chloride of lead as a deodoriser and disinfectant, and only trust that they may be sufficient to lead my readers to continue the experiments in different directions, as I have hitherto found it to be the most simple, the most economical, and most successful of all the processes which have come under my notice.

Sussex-gardens, w.

\section{CASE OF}

\section{GUNSHOT WOUND (BY DERRINGER PISTOL) OF CHEST AND ABDOMEN. AUTOPSY AND REMARKS.}

BY RICHARD BARWELL, F.R.C.S., SURGHON TO CHARING-CROSB HOSPTAL.

A. B., aged twenty-one, shot himself with a Derringer pistol about 11 o'clock on the night of Nov. 14th, 1875. Dr. Reece saw him immediately after the injury, and directed his removal to Charing-cross Hospital. I was sent for, and arrived a little before 12 o'clock that night.

The young man had been sick instantly on receipt of the injury, and was in a state of considerable though not severe collapse. A round black wound, about the size of a sixpence, from which trickled down a drop or two of dark-coloured blood, lay over the cartilage of the left eighth rib about four inches from the sternum. No probe could be passed into this opening save for a few lines immediately below the skin, in a direction upwards and outwards. He complained of no pain except at the left acromion, where it was severe.

The Derringer is a very small toy-like weapon, about five inches and a half long, with a bore of four-tenths of an inch in diameter. It is a breech-loader. The cartridge consists of a copper cap, into the open end of which the conical bullet fits, the detonating powder being, of course, at the closed end. The fulminate is of very powerful quality, and a certain specified charge is put into each cartridge. No other propellent is, I am informed, ever added.

Finding, however, at the wound no passage inwards, I thought it well that a search should be made in the young gentleman's clothing, and elsewhere in his lodgings for the bullet, but nothing was found either there or among the undigested portions of food which he had vomited.

Nov. 15th.-This morning the collapse was deeper; he had been constantly thirsty, taking ice in lumps, brandyand-water, and was also frequently vomiting. I again failed in passing any probe, and explained to my class that the bullet had in all probability passed through the cartilage, which had then closed again behind it like a trap-door. He complained of inability to pass urine, though the nurse said he was constantly doing so. There was no blood either in this excretion nor in the romit. About 8 P.M. that evening he suddenly had a greater fil of vomiting, and the matter seemed to contain a little blood. He almost instantly died.

Post-mortem (Nov. 18th). - The body was much swollen, and the skin much discoloured, though there was less decomposition in deeper parts. The wound still refused to admit a probe (of course no force was used). On taking away the front of the chest the bruising and blackening was seen to occupy a greater space on the internal than on the external surface. For a long time no opening marking the track of the bullet could be found, although the pericardium, lungs, \&c., were examined with the utmost care. At last a small slit was found in the diaphragm with no mark of bruising or extravasation around it. It was barely a third of an inch long, and only to be detected on very careful search. Of course this led into the abdomen, and on opening that cavity a little bole in the stomach was found, and on its posterior wall another; both these openings had a very narrow dark edging of extravasation. Removing the stomach, all trace of the bullet was lost; neither on the rat behind that organ nor elsewhere could any opening be found. The kidney was now removed, and in its upper and inner edge, just in front of the suprarenal capsule, a small crack or chasm was found, the extreme margin of which was blackened by extravasation. Behind the kidney, after careful search, a little split or rift was found in the fascia covering the psoas ; it was not stained by effused blood. The probe when passed into this ran backward and a little upward, and on dividing the parts the bullet was found imbedded behind the muscle just above the transverse process of the second lumbar vertebra, its conical end directed almost directly upwards. On trying the bullet on the blackened spot on the eighth costal cartilage, it was found that by exercising rather considerable pressure it could be made to pass through a hole formed by three convergent rifts, which, instantly after the passage, snapped together again like the flaps of a valve, and left no hole nor perceptible trace of passage.

It appears to me that this case is of interest as exemplifying the fearful power of the little pistol-a thing which a man might conceal easily in his clinched fist, and which looks less formidable than many' a child's toy; yet it propelled its shot all but through a full-sized man; and, as $\mathbb{E}$ saw, it will send a bullet nearly through an inch-thick oak board, shattering to a great distance the wood around its place of exit.

The next singular point is the very little injury the bullet did to the traversed tissues. The wounds in such vascular organs as the stomach and kidney had a dark margin of bruising less wide than the hem of a lady's handkerchief; but parts less richly supplied with blood showed merely minute slits where the bullet had passed, and among fat, as that round the kidney, no track could be found at all.

The symptom, a prominent one throughout, pain at the acromion, must, I think, be ascribed to wound of the dia phragm; the strangury to wound of the kidney.

George-street, Hanover-square.

REPORT ON THE

\section{EFFECTS OF HIGH TEMPERATURES UPON WOOLLEN AND OTHER FABRICS.}

\section{By Surgeon.Major F. DE Chadmont, M.D.,} CONJOINT PBOTBSBOR OF HYGIENE, $\triangle \mathrm{RMYX}$ MYDICAL SCHOOX.

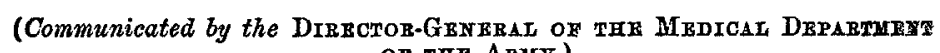
OF THE ARMY.)

IN accordance with the Director.General's instructions of Oct. 18th, 1875, I have the honour to report as follows. The portions of fabrics selected were obtained from the store here, being condemned clothing \&c., as under :-

1. Blanket-woollen, white.

2. Coverlets-woollen, coloured.

3. Hospital clothing-flannel, blue.

4. Sheeting-cotton.

5. Bed-slip-canvas.

6. Hospital lining-cotton.

7. Horsehair from mattress.

These were exposed as follows:-

Dry heat, $212^{\circ} \mathrm{F}$., for 2 hours

\begin{tabular}{|c|c|c|c|}
\hline ", & " & $\Rightarrow 4$ & $"$ \\
\hline "פ, & $220^{\circ} \mathrm{F}$ & $\Rightarrow 6$ & $"$ \\
\hline & $220 \mathrm{~F}$ & $" 2$ & " \\
\hline נ, & $\ddot{\prime \prime}$ & $" \begin{array}{ll}4 \\
" & 6\end{array}$ & 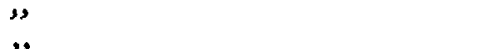 \\
\hline & " & , 44 & $8+15+15+6$ hours) on \\
\hline & $230^{\circ} \mathrm{F}$. & , 8 & "Total, 13 hours on an iroz \\
\hline & " & $\Rightarrow 5$ & plate on successive days \\
\hline & $"$ & & otal, 14 hrs. on a porcelain: \\
\hline & $250^{\circ} \mathrm{F}$. & $\Rightarrow 4$ & $"$ Total, 9 hours on sue- \\
\hline & " & $\Rightarrow 5$ & "f cessive days. \\
\hline
\end{tabular}

The following results were observed on comparing the samples with the fabrics in their original condition :- 